\title{
CALCULATION OF VIBRATIONAL SPECTRA FOR DIOXOURANIUM MONOCHLORIDE MONOMER AND DIMERS
}

\author{
D. S. Umreiko, ${ }^{a}$ M. B. Shundalau, ${ }^{b^{*}}$ A. P. Zazhogin, \\ and A. I. Komyak
}

UDC 539.19

Structural models were built and spectral characteristics were calculated based on ab initio calculations for the monomer and dimers of dioxouranium monochoride $\mathrm{UO}_{2} \mathrm{Cl}$. The calculations were carried out in the effective core potential LANL2DZ approximation for the uranium atom and all-electron basis sets using DFT methods for oxygen and chlorine atoms (B3LYP/cc-pVDZ). The monomer $\mathrm{UO}_{2} \mathrm{Cl}$ was found to possess an equilibrium planar (close to T-shaped) configuration with $C_{2 v}$ symmetry. The obtained spectral characteristics were analyzed and compared with experimental data. The adequacy of the proposed models and the qualitative agreement between calculation and experiment were demonstrated.

Keywords: ab initio calculations, effective core potential, IR spectrum, dioxouranium monochloride.

Introduction. The actinide elements react with oxygen to form many stoichiometric and non-stoichiometric compounds. In this respect, the uranium-oxygen system is unparalleled in complexity. Uranium behaves as a multivalent element in compounds with oxygen and forms stoichiometric and non-stoichiometric phases, some of which are unstable at room temperature [1-3].

Despite the variety of uranium oxides, only three are commonly mentioned in the literature: $\mathrm{UO}_{2}, \mathrm{U}_{3} \mathrm{O}_{8}$, and $\mathrm{UO}_{3}$. These have high practical significance because they are the most important intermediates for producing uranium metal and its fluorides among such compounds as ammonium uranyl nitrate dihydrate, uranium peroxide, and ammonium uranyl tricarbonate. One of the most important applications of $\mathrm{UO}_{2}$ is in fuel rods of many types of modern nuclear reactors. $\mathrm{UO}_{2}$, being a ceramic fuel for nuclear reactors, is highly resistant to corrosion, radiation, and heat. This makes it possible to attain significantly higher temperatures in reactors than if metallic uranium were used $[4,5]$. The principal method for synthesizing $\mathrm{UO}_{2}$ is calcination of uranium salts with subsequent reduction [4]. The drawbacks of this method are the many steps and duration in addition to the use of high temperatures (up to $2000 \mathrm{~K}$ ) and explosive oxygen. Another convenient method for synthesizing $\mathrm{UO}_{2}$ is direct reduction of uranyl nitrate hexahydrate in a saturated alcohol solution in an autoclave at $473-453 \mathrm{~K}$ for $0.5-1.0 \mathrm{~h}$. The proposed methods for synthesizing $\mathrm{UO}_{2}$ could simplify the process and decrease significantly its temperature and time.

One of the reaction products of $\mathrm{UO}_{2}$, for example, with halogens, is dioxouranium monochloride $\mathrm{UO}_{2} \mathrm{Cl}$, which has definite practical value $[3,4]$ and is a water-insoluble dark-brown compound. The DTA curve of $\mathrm{UO}_{2} \mathrm{Cl}$ (Fig. 3, curve 1 in [6]) shows one endotherm at $665^{\circ} \mathrm{C}$. The TG curve (curve 2 of the same reference) contains a mass loss of $11.5 \%$ in the temperature range $620-710^{\circ} \mathrm{C}$. Analysis of the thermogram for $\mathrm{Cl}$ showed that the only endotherm corresponded to loss of one mole of $\mathrm{Cl}$. The final decomposition product according to chemical and $\mathrm{x}$-ray analyses was $\mathrm{UO}_{2}$.

Therefore, it seemed interesting to determine the spectral and structural features of $\mathrm{UO}_{2} \mathrm{Cl}$ in order to use them for analytical purposes. Keeping in mind the possibility of forming a polymeric system [6], we examine $\mathrm{UO}_{2} \mathrm{Cl}$ monomer and dimers, the latter as a model of the simplest fragment of the polymeric structure.

*To whom correspondence should be addressed.

${ }^{\mathrm{a}}$ A. N. Sevchenko Institute of Applied Physical Problems, Belarusian State University, Minsk; e-mail: lab_dozator@mail.ru; ${ }^{b}$ Belarusian State University, 4 Nezavisimosti Ave., Minsk, 220030, Belarus: e-mail: shundalov@bsu.by. Translated from Zhurnal Prikladnoi Spektroskopii, Vol. 77, No. 4, pp. 550-555, July-August, 2010. Original article submitted March 26, 2010. 


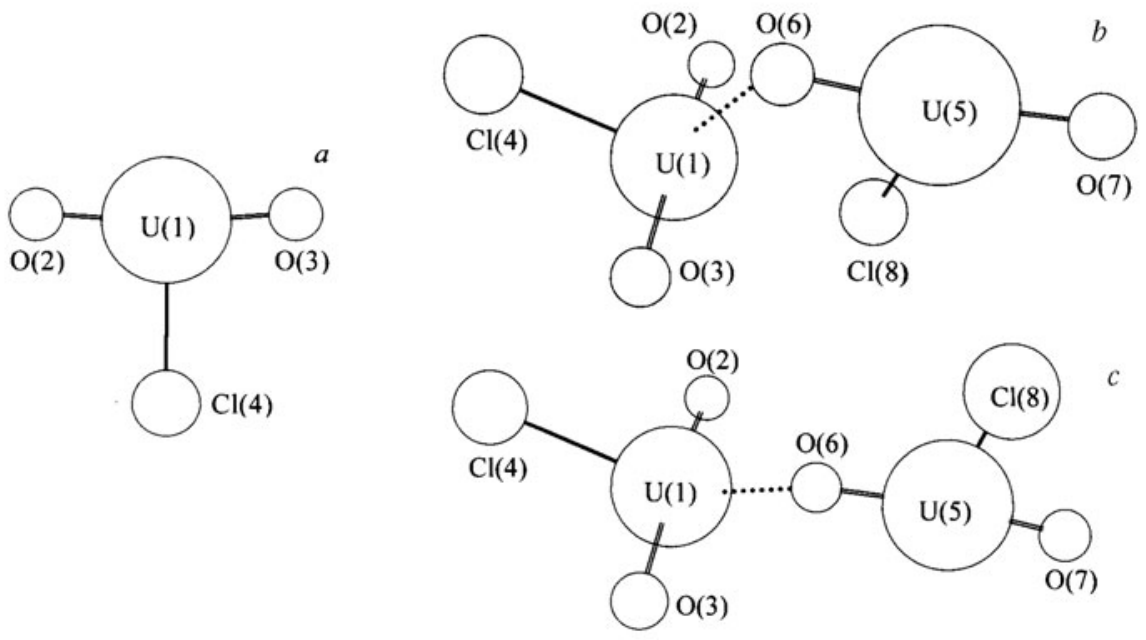

Fig. 1. Equilibrium structures of $\mathrm{UO}_{2} \mathrm{Cl}$ monomer (a) and dimers I and II (b and c).

Results and Discussion. The structure of $\mathrm{UO}_{2} \mathrm{Cl}$ monomer (Fig. 1a) was modeled based on results of numerous investigations of hexavalent uranium compounds [7, 8], for which the basic structural element is $\mathrm{UO}_{2}^{2+}$ (so-called uranyl ion). Uranyl is a linear complex of high symmetry. This has been proven by direct methods (neutron diffraction) and by spectroscopy (the alternative forbidden rule is obeyed well). However, the $\mathrm{UO}_{2}^{2+}$ group can also have nonlinear geometry if the symmetry is lowered (for example, with a non-uniform equatorial ligand environment around $\mathrm{UO}_{2}^{2+}$ or by establishing additional bonds through polymerization). As a result, all frequencies of this structural unit are activated in the vibrational spectra (IR absorption and Raman). Keeping in mind that the experimental spectrum of $\mathrm{UO}_{2} \mathrm{Cl}$ exhibits two strong absorption bands [6] near 850 and $950 \mathrm{~cm}^{-1}$ (characteristic of uranyl ion in complexes [7]), we hypothesized that $\mathrm{UO}_{2} \mathrm{Cl}$ may contain a similar analog of this group. The fact that the aforementioned frequencies are active in the IR absorption spectrum (the alternative forbidden rule is violated) indicates that the $\mathrm{UO}_{2}$ group in the monomer is bent; the fact that they are split into two components each, that these groups are nonequivalent in the actual structure or that their shoulders are significantly asymmetric because of the different environments of the axial oxygens in a field of rather low symmetry. Such an effect was also observed in uranyl compounds, especially when the equatorial environment of $\mathrm{UO}_{2}^{2+}$ is unsaturated and additional bonds between the complexes are formed through the uranyl $\mathrm{O}$ atom [7]. This suggested that the simplest bound systems may exist as dimers.

The structures and spectral characteristics of $\mathrm{UO}_{2} \mathrm{Cl}$ monomer and dimers were calculated using the applied quantum-chemical program GAMESS-US [9, 10]. Results were visualized using the program MacMolPlt [11]. Calculations were performed using DFT methods with pseudo-potentials or effective core potentials (ECP) [12]. A certain number of inner (core) electrons is replaced by the pseudo-potential. The LANL2DZ ECP, which replaces the 78 core electrons of the uranium atom, was used as the effective core potential [13]. DZ-basis sets that were specially developed for this ECP were used for the remaining electrons. The $\mathrm{O}$ and $\mathrm{Cl}$ atoms were described based on the standard fully electronic basis set cc-pVDZ [14]. Pseudo-potentials and the corresponding basis sets were generated using the Extensible Computational Chemistry Environment Basis Set Database [15-17]. The hybrid exchange-correlated functional B3LYP was used in all calculations [18, 19].

The geometry was optimized and the vibrational spectrum of the isolated uranyl ion $\mathrm{UO}_{2}^{2+}$, for which a stable linear configuration was obtained, was calculated in a preliminary stage in order to estimate the accuracy of the aforementioned approximations for the examined species. The UO bond length was $1.709 \AA$ . The frequency of the $\mathrm{UO}_{2}$ anti-symmetric stretching vibration $v_{3}=1102 \mathrm{~cm}^{-1}$; fully symmetric $v_{1}=1006 \mathrm{~cm}^{-1}$; bending $v_{2}=259 \mathrm{~cm}^{-1}$. Experimental data on the structure and vibrational frequencies of free uranyl ion have not been published. The UO bond length for uranyl complexes lies in the range 1.60-1.95 $\AA$, depending on the environment. Frequency $v_{3}=800-1020$ $\mathrm{cm}^{-1} ; v_{1}=780-900 \mathrm{~cm}^{-1} ; v_{2}=190-210 \mathrm{~cm}^{-1}[7,8,20]$. The ratio of $v_{3}$ and $v_{1}$ for a whole range of compounds 


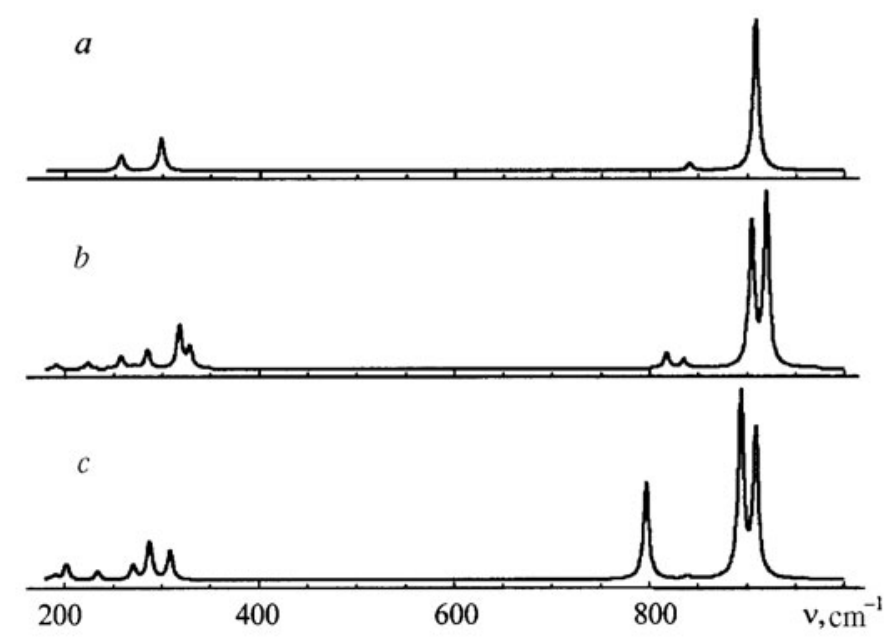

Fig. 2. Calculated IR spectra of $\mathrm{UO}_{2} \mathrm{Cl}$ monomer (a) and dimers I and II (b and c).

TABLE 1. Equilibrium Geometric Parameters of $\mathrm{UO}_{2} \mathrm{Cl}$ Monomer and Dimers

\begin{tabular}{|c|c|c|c||}
\hline \multirow{2}{*}{ Parameter } & \multirow{2}{*}{ Monomer } & \multicolumn{2}{|c|}{ Dimer } \\
\cline { 2 - 4 } & & I & II \\
\hline $\mathrm{U}(1) \mathrm{O}(2)$ & 1.796 & 1.809 & 1.808 \\
$\mathrm{U}(1) \mathrm{O}(3)$ & 1.796 & 1.809 & 2.659 \\
$\mathrm{U}(1) \mathrm{Cl}(4)$ & 2.642 & 2.687 & 1.845 \\
$\mathrm{U}(5) \mathrm{O}(6)$ & - & 1.819 & 1.789 \\
$\mathrm{U}(5) \mathrm{O}(7)$ & - & 1.786 & 2.600 \\
$\mathrm{U}(5) \mathrm{Cl}(8)$ & - & 2.668 & 2.591 \\
$\mathrm{U}(1) \mathrm{O}(6)$ & - & 2.645 & 4.379 \\
$\mathrm{U}(1) \ldots \mathrm{U}(5)$ & - & 3.993 & 94.39 \\
$\mathrm{O}(2) \mathrm{U}(1) \mathrm{Cl}(4)$ & 93.91 & 92.53 & 94.39 \\
$\mathrm{O}(3) \mathrm{U}(1) \mathrm{Cl}(4)$ & 93.91 & 92.53 & 95.26 \\
$\mathrm{O}(6) \mathrm{U}(5) \mathrm{Cl}(8)$ & - & 86.35 & 98.62 \\
$\mathrm{O}(7) \mathrm{U}(5) \mathrm{Cl}(8)$ & - & 102.46 & 115.49 \\
$\mathrm{Cl}(4) \mathrm{U}(1) \mathrm{O}(6)$ & - & 104.47 & 161.26 \\
$\mathrm{U}(1) \mathrm{O}(6) \mathrm{U}(5)$ & - & 125.89 & \\
\hline
\end{tabular}

remained at approximately 1.08 [7]. Extrapolation of existing experimental and calculated data for free uranyl ion predict $v_{3}=1116 \mathrm{~cm}^{-1}[21,22]$. Then, $v_{1}$ should be expected to be $926 \mathrm{~cm}^{-1}$.

Thus, our calculation of free uranyl ion demonstrated that the selected approximation was adequate and that the agreement of experimental and theoretical data obtained using different pseudo-potentials, basis sets, and exchangecorrelated functionals was very satisfactory [20].

We performed $a b$ initio quantum-chemical calculations of the structure of vibrational spectra of $\mathrm{UO}_{2} \mathrm{Cl}$ monomer. A non-planar pyramidal structure with point symmetry $C_{1}$ was set as the initial configuration during a search for the equilibrium configuration of the monomer. Nevertheless, the geometry optimization produced a planar (close to T-shaped) configuration of symmetry $C_{2 v}$ (Fig. 1a). Table 1 presents the calculated geometric parameters of $\mathrm{UO}_{2} \mathrm{Cl}$ 
TABLE 2. Calculated Frequencies $\left(v, \mathrm{~cm}^{-1}\right)$ and Intensities $\left(I, D^{2} / \mathrm{amu} / \AA^{2}\right)$ in IR Vibrational Spectra of $\mathrm{UO}_{2} \mathrm{Cl}$ Monomer and Dimers

\begin{tabular}{|c|c|c|c|c|c|c|}
\hline \multirow{3}{*}{ Assignment of vibrations } & \multirow{2}{*}{\multicolumn{2}{|c|}{ Monomer }} & \multicolumn{4}{|c|}{ Dimer } \\
\hline & & & \multicolumn{2}{|c|}{ I } & \multicolumn{2}{|c|}{ II } \\
\hline & $v$ & $I$ & $v$ & $I$ & $v$ & $I$ \\
\hline $\begin{array}{l}\text { Stretching, anti-symmetric, } \mathrm{UO}_{2} \text { core } \\
\text { fragment (monomer) }\end{array}$ & 908.9 & 9.00 & 904.9 & 8.58 & 909.4 & 8.81 \\
\hline Stretching, anti-symmetric, $\mathrm{UO}_{2}$ satellite & - & - & 920.0 & 10.30 & 894.3 & 11.13 \\
\hline $\begin{array}{l}\text { Stretching, symmetric, } \mathrm{UO}_{2} \text { core } \\
\text { fragment (monomer) }\end{array}$ & 841.1 & 0.41 & 835.4 & 0.56 & 839.6 & 0.21 \\
\hline Stretching, symmetric, $\mathrm{UO}_{2}$ satellite & - & - & 817.9 & 0.93 & 797.1 & 5.85 \\
\hline $\begin{array}{l}\text { Stretching, } \mathrm{UCl} \text { core fragment } \\
\text { (monomer) }\end{array}$ & 298.7 & 1.94 & 258.0 & 0.54 & 287.8 & 2.30 \\
\hline Stretching, UCl satellite & - & - & 271.3 & 0.17 & 309.0 & 1.72 \\
\hline $\begin{array}{l}\text { Out-of-plane, symmetric, OUO core } \\
\text { fragment (monomer) }\end{array}$ & 257.2 & 0.88 & 285.2 & 1.13 & 271.0 & 0.84 \\
\hline $\begin{array}{l}\text { Out-of-plane, symmetric, OUO satellite } \\
\text { and out-of-plane, anti-symmetric } \\
\text { OUO core fragment }\end{array}$ & - & - & 258.1 & 0.20 & 234.1 & 0.49 \\
\hline $\begin{array}{l}\text { Bending, symmetric, } \mathrm{OUCl} \text { core } \\
\text { fragment (monomer) }\end{array}$ & 250.2 & 0.06 & 328.8 & 1.27 & 202.0 & 0.95 \\
\hline Bending, symmetric, $\mathrm{OUCl}$ satellite & - & - & 318.3 & 2.56 & 185.1 & 0.14 \\
\hline $\begin{array}{l}\text { Bending, anti-symmetric, } \\
\text { OUCl core fragment (monomer) }\end{array}$ & 172.2 & 0.01 & 223.9 & 0.35 & 190.9 & 0.23 \\
\hline Bending, anti-symmetric, $\mathrm{OUCl}$ satellite & - & - & 191.3 & 0.15 & 99.4 & 0.05 \\
\hline Torsional, satellite w.r.t. core fragment & - & - & 190.3 & 0.12 & 123.2 & 0.01 \\
\hline Torsional, satellite w.r.t. core fragment & - & - & 124.7 & 0.01 & 116.9 & 0.02 \\
\hline Bending, U...OU & - & - & 111.7 & 0.20 & $84.0 \mathrm{i}$ & - \\
\hline "Stretching", U...O & - & - & 76.8 & 0.02 & 69.5 & 0.06 \\
\hline Swinging, UCl w.r.t. U...OU plane & - & - & 75.0 & 0.16 & $9.4 \mathrm{i}$ & - \\
\hline Bending, O...UCl & - & - & 30.8 & 0.17 & 20.4 & 0.14 \\
\hline
\end{tabular}

monomer (bond lengths are given in $\AA$, angles in degrees). A calculation of the force-constant matrix and vibrational frequencies, which demonstrated the imaginary frequencies were absent, confirmed that this configuration was stable. The ion $\mathrm{UO}_{2} \mathrm{~F}^{+}$has an analogous structure [23].

Figure 2a shows the calculated vibrational IR spectrum of $\mathrm{UO}_{2} \mathrm{Cl}$ monomer. Table 2 lists assignments of vibrational frequencies for certain types of vibrations and intensities of the corresponding absorption bands.

The presence of a $\mathrm{Cl}$ atom bonded to uranium perturbs the linearity of the $\mathrm{UO}_{2}$ group $\left(\angle \mathrm{OUCl}=93.91^{\circ}\right)$. Therefore, it should be expected that the fully symmetric $\mathrm{O}=\mathrm{U}=\mathrm{O}$ stretching vibration is active in the IR absorption spectrum. This was observed experimentally [6]. The first two strongest high-frequency bands correspond to just these $\mathrm{UO}_{2}$ stretching vibrations. The frequency $298.7 \mathrm{~cm}^{-1}$ was assigned to the $\mathrm{UCl}$ stretching vibration. This was confirmed in spectra of uranyl tetrachloride $\left(264 \mathrm{~cm}^{-1}\right)$ (Tables 2 and 3 in [7]). It is noteworthy that the previous assignment was made a priori [7]. Moreover, the uranyl ion was surrounded by four $\mathrm{Cl}$ atoms and not one as in the examined species. Therefore, it should be expected that the vibrational frequency involving the $\mathrm{Cl}$ atom in the latter case would be higher than in uranyl tetrachloride. Finally, $\mathrm{UO}_{2}$ bending vibrations were in the range $170-260 \mathrm{~cm}^{-1}$. This corresponded to the generally accepted values. 
Let us turn to $\mathrm{UO}_{2} \mathrm{Cl}$ dimers and their IR absorption spectra. The geometry of $\mathrm{UO}_{2} \mathrm{Cl}$ dimer was optimized assuming that it had $C_{s}$ symmetry with one of the monomeric fragments lying in the symmetry plane of the dimer and the second perpendicular to it. Figure $1 \mathrm{~b}$ and $\mathrm{c}$ shows the two structures found for $\mathrm{UO}_{2}$ dimer. Table 1 presents their geometric parameters. Dimer I was more stable. Its total energy was $41 \mathrm{~kJ} / \mathrm{mol}$ less than that of dimer II. It is noteworthy that the structure of the $\mathrm{U}(1) \mathrm{O}(2) \mathrm{O}(3) \mathrm{Cl}(4) \ldots \mathrm{O}(6)$ moiety in both dimers was similar to that of $\mathrm{UO}_{2} \mathrm{~F}_{2}$ [23]. The presence of two imaginary frequencies in the calculated vibrational spectrum of dimer II (Table 2) can be explained by symmetry constraints imposed on the molecular structure during optimization of its geometry.

The insignificant changes in interatomic distances and $\mathrm{OUCl}$ angles for one of the monomeric fragments constituting the dimer (which we call "reference") with respect to the monomer deserves special mention. Also, the interatomic distances of the second monomeric fragment ("satellite") undergo substantial changes with the $\mathrm{O}(6) \mathrm{U}(5) \mathrm{Cl}(8)$ and $\mathrm{O}(7) \mathrm{U}(5) \mathrm{Cl}(8)$ angles becoming unequal. This is caused by the formation of an intermolecular (dimeric) $\mathrm{U}(1) \ldots \mathrm{O}(6) \mathrm{U}(5)$ bond. The analysis of the structure of $\mathrm{UO}_{2} \mathrm{Cl}$ dimers showed that the structures of the reference monomeric fragment and its satellite were different. This should be evident in the vibrational spectra of $\mathrm{UO}_{2} \mathrm{Cl}$ dimers compared with that of the monomer. The presence in $\mathrm{UO}_{2} \mathrm{Cl}$ dimer of two nonequivalent monomeric fragments should produce doubled frequencies for the stretching vibrations (absorption bands). This was in fact observed in the calculation (Table 2, Fig. $2 \mathrm{~b}$ and c) and experimentally (Fig. 4, curve 2 in [6]). Weak bands for $\mathrm{UO}_{2}$ bending vibrations may appear in the appropriate spectral region $\left(200-300 \mathrm{~cm}^{-1}\right)$. Bands corresponding to $\mathrm{UCl}$ stretching vibrations and bending vibrations involving $\mathrm{Cl}$ atoms will appear here also.

The region $450-750 \mathrm{~cm}^{-1}$ in the experimental spectrum remains difficult to explain [6]. One possible reason for the appearance of absorption here could be overtones and combination frequencies involving $\mathrm{Cl}$ atoms. At least, the bending vibration of the oxygen bridge $\mathrm{U}(1) \ldots \mathrm{O}(6) \mathrm{U}(5)$ lies according to our calculations much lower than this region and can hardly be explained by an error in the force field. However, if the examined dimers are considered to be fragments of more complicated and varied constructions (polymers), then the conditions for forming a more complicated spectrum may arise. An example of this is the symmetric $\mathrm{UO}_{2}$ stretching vibration of the satellite in model dimer II. The absorption band corresponding to this vibration $\left(797 \mathrm{~cm}^{-1}\right)$ undergoes a long-wavelength shift by $44 \mathrm{~cm}^{-1}$ relative to its position in the spectrum of the monomer $\left(841 \mathrm{~cm}^{-1}\right)$. Its intensity increases by an order of magnitude and becomes comparable with that of bands for anti-symmetric vibrations.

Conclusion. The proposed models and method for calculating the vibrational spectrum structure of $\mathrm{UO}_{2} \mathrm{Cl}$ dimer describe at least qualitatively the actual system and can be used as a basis for further analysis of its spectral characteristics.

\section{REFERENCES}

1. V. M. Vdovenko, Chemistry of Uranium and Transuranium Elements [in Russian], Atomizdat, Moscow (1960).

2. V. G. Vlasov, V. M. Zhukovskii, E. B. Tkachenko, and A. R. Beketov, Oxygen Compounds of Uranium [in Russian], Atomizdat, Moscow (1972).

3. J. J. Katz and E. Rabinowitch, The Chemistry of Uranium, Part 1, McGraw-Hill Book Co., New York (1951).

4. B. V. Gromov, Introduction to Uranium Chemical Technology [in Russian], Atomizdat, Moscow (1978).

5. A. S. Zaimovskii, V. V. Kalashnikov, and I. S. Golovin, Atomic Reactor Fuel Rods [in Russian], Atomizdat, Moscow (1966).

6. A. P. Zazhogin, A. I. Komyak, D. S. Umreiko, and S. D. Umreiko, Zh. Prikl. Spektrosk., 77, No. 2, 274-279 (2010).

7. L. V. Volod'ko, A. I. Komyak, and D. S. Umreiko, Uranyl Compounds [in Russian], 1, Bel. Gos. Univ., Minsk (1981).

8. D. S. Umreiko, T. A. Dik, A. P. Zazhogin, A. I. Komyak, and V. V. Syt'ko, Spectra and Structure of Uranyl Complexes [in Russian], Bel. Gos. Univ., Minsk (2004).

9. http://www.msg.ameslab.gov/GAMESS/GAMESS.html

10. M. W. Schmidt, K. K. Baldridge, J. A. Boatz, S. T. Elbert, M. S. Gordon, J. H. Jensen, S. Koseki, N. Matsunaga, K. A. Nguyen, S. J. Su, T. L. Windus, M. Dupuis, and J. A. Montgomery, J. Comput. Chem., 14, 13471363 (1993). 
11. B. M. Bode and M. S. Gordon, J. Mol. Graph. Modell., 16, 133-138 (1998).

12. M. Krauss and W. J. Stevens, Annu. Rev. Phys. Chem., 35, 357-385 (1984).

13. L. R. Kahn, P. J. Hay, and R. D. Cowan, J. Chem. Phys., 68, 2386-2397 (1978).

14. T. H. Dunning, Jr., J. Chem. Phys., 90, 1007-1023 (1989).

15. https://bse.pnl.gov/bse/portal

16. D. Feller, J. Comput. Chem., 17, 1571-1586 (1996).

17. K. L. Schuchardt, B. T. Didier, T. Elsethagen, L. Sun, V. Gurumoorthi, J. Chase, J. Li, and T. L. Windus, J. Chem. Inf. Model., 47, 1045-1052 (2007).

18. A. D. Becke, J. Chem. Phys., 98, 5648-5652 (1993).

19. C. Lee, W. Yang, and R. G. Parr, Phys. Rev. B: Condes. Matter, 37, 785-789 (1988).

20. W. A. de Jong, R. J. Harrison, J. A. Nichols, and D. A. Dixon, Theor. Chem. Acc., 107, 22-26 (2001).

21. G. S. Groenewold, A. K. Gianotto, K. C. Cossel, M. J. Van Stopdonk, D. T. Moore, N. Polfer, J. Oomens, W. A. de Jong, and L. Visscher, J. Am. Chem. Soc., 128, 4802-4813 (2006).

22. R. G. Denning, J. Phys. Chem. A, 111, 4125-4143 (2007).

23. M. Straka, K. G. Dyall, and P. Pyykko, Theor. Chem. Acc., 106, 393-403 (2001). 